\title{
Conceptual Analyses of Waste Dump Options Used to Prepare a Detailed Progressive Waste Dump Life-of-Mine Plan
}

\author{
N.C. Journet DumpSolver Pty Ltd, Australia
}

\begin{abstract}
The paper describes a study recently undertaken to analyse waste dump options and prepare a detailed waste dump strategy for an open pit project. The open pit is expected to produce around 220 million bcm of waste rock over an 18 year mine life. The study was carried out in three phases. The first phase was an options analysis which considered the impact on dumping costs of releasing progressively larger areas of terrain as potential waste dump footprint. Some of these areas had previously been described as environmentally sensitive and the client wished to examine the economic impact of preserving such areas.
\end{abstract}

One portion of the lease identified in the options analysis is prime dump footprint but has not yet been sterilised. The second phase examined the impact on cash flow from higher dumping costs if the sterilisation programme were to be delayed by 12 or 24 months.

The final phase used results from the earlier work to develop a detailed dumping sequence to develop the landform over the life of the project.

The study shows how a robust operating plan for a rock dump can be developed by first understanding the conceptual parameters likely to impact the overall landform.

\section{Introduction}

This is a green-field development which is expected to have a mine life of 18 years and with associated ore, will mine some 220 million bcm of waste rock from an excavation which will eventually be $400 \mathrm{~m}$ deep, $2 \mathrm{~km}$ long and $1 \mathrm{~km}$ wide. The overall strip ratio for the project is approximately 3.5:1.

Ore and waste will be excavated by conventional open pit mining methods using EX1900 hydraulic shovels with a fleet of Caterpillar $77795 \mathrm{t}$ trucks. The open pit is located on the eastern flank of a ridge which is about $35 \mathrm{~m}$ above the surrounding topography. The terrain on the east falls away gradually to a large ephemeral wetland system. The ridge line itself marks a national boundary which obviates the western side of the pit as a potential waste landform site. The treatment plant was located on the south side of the open pit largely since this area presented the most competent platform on which to construct the plant.

Consequently, zones to the north provide the major and most obvious footprint for the waste landform. The narrow portion strip between the eastern wall of the pit and the wetland area provides some potential to expand the waste footprint but will be subject to additional environmental approvals.

The waste landform planning was undertaken in three phases. The first phase was a broad options study which examined the economic impact of progressively releasing larger areas in the northern zone to be available footprint for the waste landform. This phase also examined the potential economic benefit of extending the landform southwards on the narrow strip of land between the eastern side of the pit and the wetland system.

The first phase evaluation established the most likely configuration of northern footprint zones. Unfortunately, one of the zones has not yet been sterilised so the second phase examined the impact of this oversight if the zone remained unavailable for 12 months or 24 months. The progressive dump blocks were developed for each scenario and then cash flows prepared to calculate the discounted cash flow and peak cash flow difference. The exercise provided a salutary lesson and quantified the true impact of less than optimal project planning. 
In broad terms, waste landforms can be constructed using one of three methods. Bench advance where lifts are constructed by placing blocks from the position nearest the pit exit to the final toe position. When the first lift is completed, the next lift is started and so on until the final "as dumped" landform is achieved. The second method is a variation on bench advance and is called bench retreat where the outermost blocks of each lift are placed first and the landform is constructed progressively back towards the pit. For mining engineers familiar with Whittle pit optimisation, these two sequencing methods are equivalent to the worst case mining schedule. The best case dumping sequence is where blocks are placed in order of increasing haulage cost. We call this NPV dumping where cheapest blocks are dumped first but to achieve it, a specific ramp system must be developed during landform construction which allows semi-permanent access to every lift in the landform. The third phase of the study describes this access system and how it was used to prepare a set of stage plans setting out the progressive development of the waste landform over the life-of-mine. NPV dumping is particularly desirable in the current climate of high commodity prices since each truck hour saved hauling waste can be used to haul ore.

\section{Economic input parameters}

All the analyses described in this paper were carried out using DumpSolver's proprietary software programmes which for a given set of physical constraints will help determine an optimal waste landform profile taking account of fixed and variable cost components of constructing the waste landform.

Fixed and variable haul components are presented as overhaul costs and expressed as $\mathrm{c} / \mathrm{bcm} / 100 \mathrm{~m}$ horizontal and $\mathrm{c} / \mathrm{bcm} / 10 \mathrm{~m}$ vertical haul. Overhaul costs take account of hourly ownership costs, fuel usage, operator labour, spares and maintenance. These costs are calculated using incremental haul analysis. For this particular project, the overhaul costs were calculated to be $2.6 \mathrm{c} / \mathrm{bcm} / 100 \mathrm{~m}$ horizontal and $5.3 \mathrm{c} / \mathrm{bcm} / 10 \mathrm{~m}$ vertical on a 1:10 ramp. This equates to an effective flat haul (EFH) of $20.4 \mathrm{~m}$. In our experience, the EFH varies between $18-30 \mathrm{~m}$ and will depend on the truck and local operating conditions. The influence of EFH on landform profile is profound since it will define the outer bench configuration. On pure haul economics, since the lift height in this case is $10 \mathrm{~m}$, the outer benches will be $204 \mathrm{~m}$ wide. This will have a massive impact on the stability and rehabilitation of the landform.

Area costs include land acquisition, topsoil clearing and storage, tip-head maintenance, haul roads across the dump, topsoil replacement, ripping, seeding etc. The area costs' influence on the final landform will reduce the outer bench width on the lower benches as the optimisation process checks to see if the footprint occupied by dump blocks on the outer walls of the landform can be more economically located elsewhere on the dump. This is referred to as clawback and unless the area cost is very high, the impact of clawback on the toe position of the final landform is relatively small. Typically, area costs vary between $A \$ 10,000$ A $\$ 50,000 / \mathrm{Ha}$.

\section{Phase 1 options analysis}

The options analysis investigated the economics of progressively enlarging the available waste landform footprint. A $100 \mathrm{~m}$ buffer around the maximum possible pit outline defined a primary constraint. Other primary constraints were formed from a $100 \mathrm{~m}$ wide buffer inside the national border, the treatment plant infrastructure which included the ROM pad.

The site layout showing the waste landform footprint zones is summarised in Figure 1. These zones are cumulative:

- $\quad$ Zone $202=202$

- Zone $707=202+707$

- Zone $404=202+707+404$

- Zone $505=202+707+404+505$

- Zone $808=202+707+404+505+808$ 


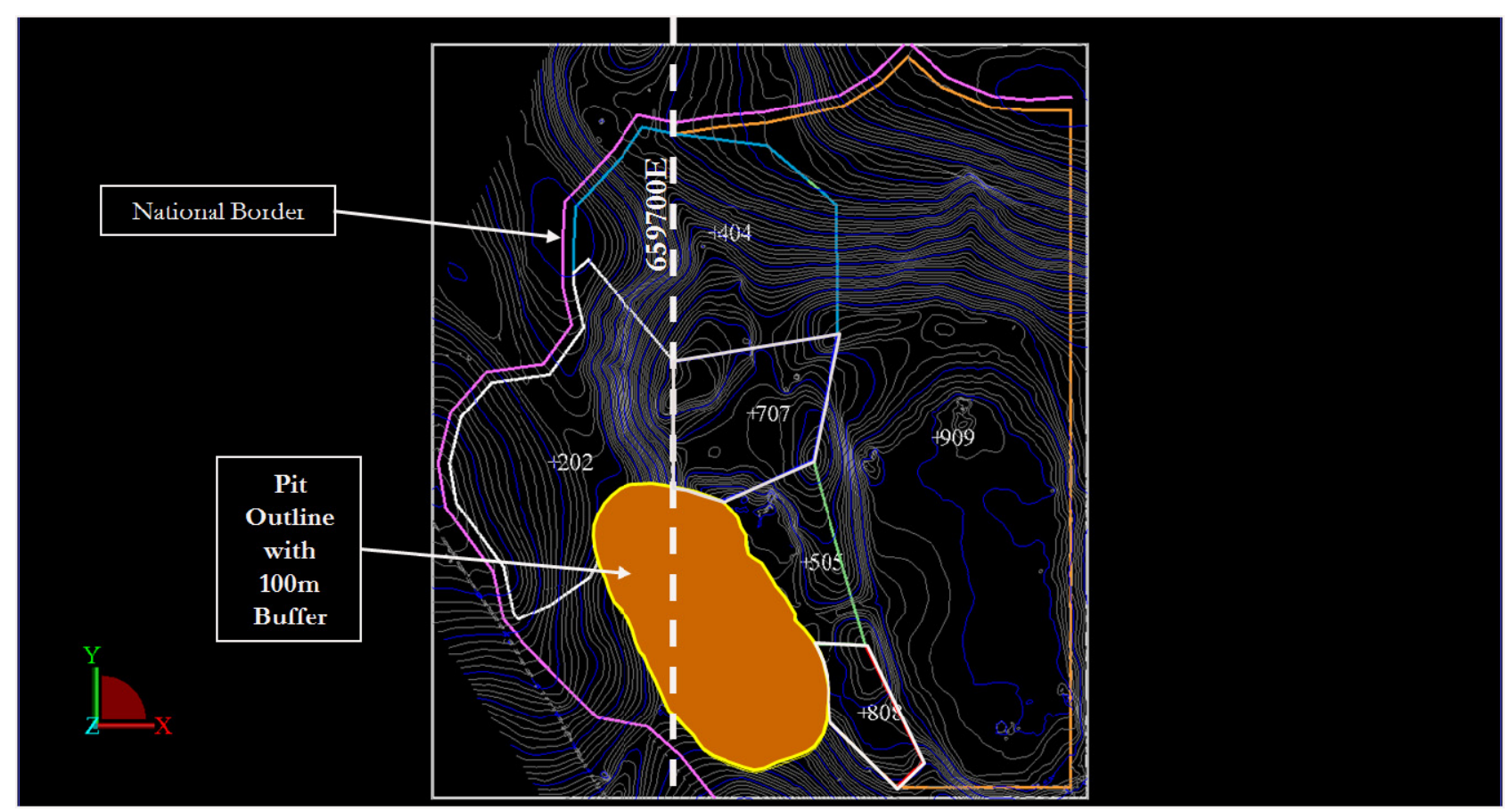

\section{Figure $1 \quad$ Waste landform constraints}

In summary, the life-of-mine schedule described weathered, partially weathered and unweathered waste materials.

Table 1 Life-of-mine waste quantities

\begin{tabular}{lccc}
\hline Material description & $\begin{array}{c}\text { In situ volume } \\
\text { (bcm) }\end{array}$ & Swell factor & $\begin{array}{c}\text { Dumped volume } \\
\text { (dcm) }\end{array}$ \\
\hline Weathered & $74,157,000$ & 1.05 & 77864,850 \\
Partially weathered & $5,531,000$ & 1.15 & $6,360,650$ \\
Unweathered & $140,402,000$ & 1.25 & $175,502,500$ \\
Total & $220,190,000$ & 1.18 & $259,728,000$ \\
\hline
\end{tabular}

The waste volumes described in Table 1 were distributed between six potential dump entry points. The quantity of material directed to each entry point was optimised for each dumping zone combination.

The developed landform plans are shown in Figure 2 and the results tabulated in Table 2. Zone 202, which was the original area earmarked for the waste dump, had insufficient capacity and was abandoned from further analysis. Note the wide benches developed on the outer walls of each landform, particularly where unconstrained. 


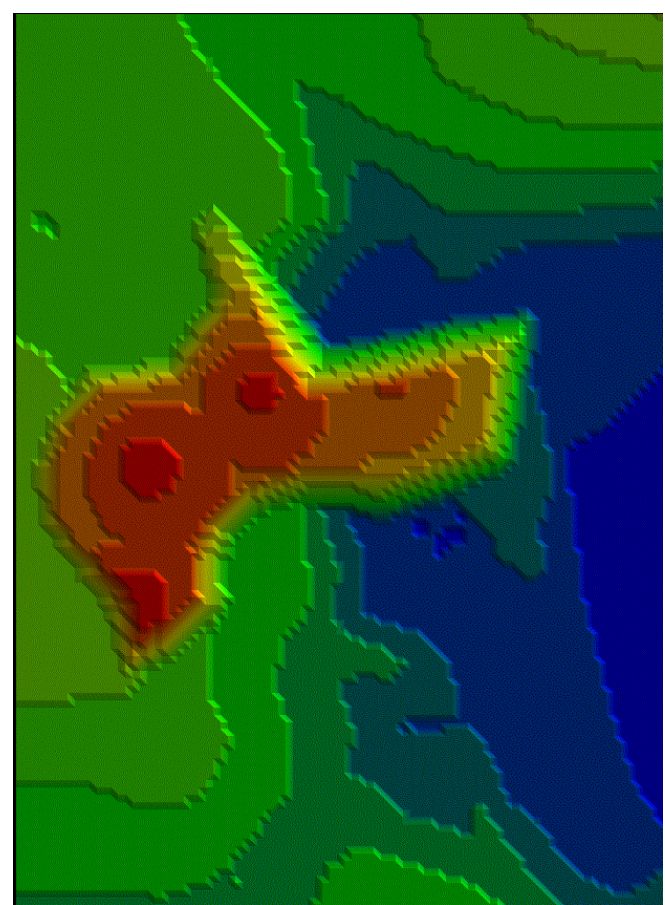

Dump profile zone 707

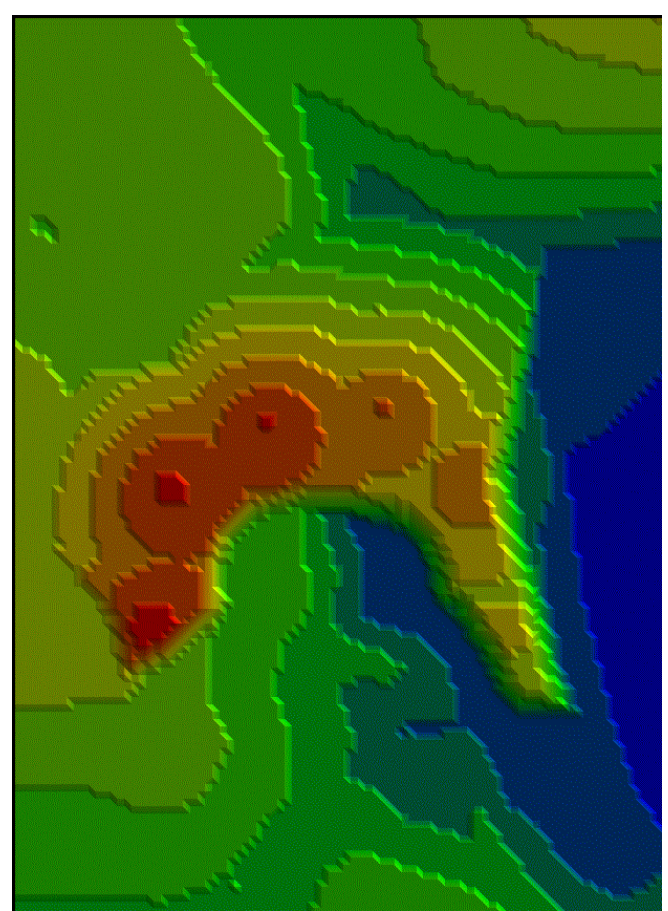

Dump profile zone 505

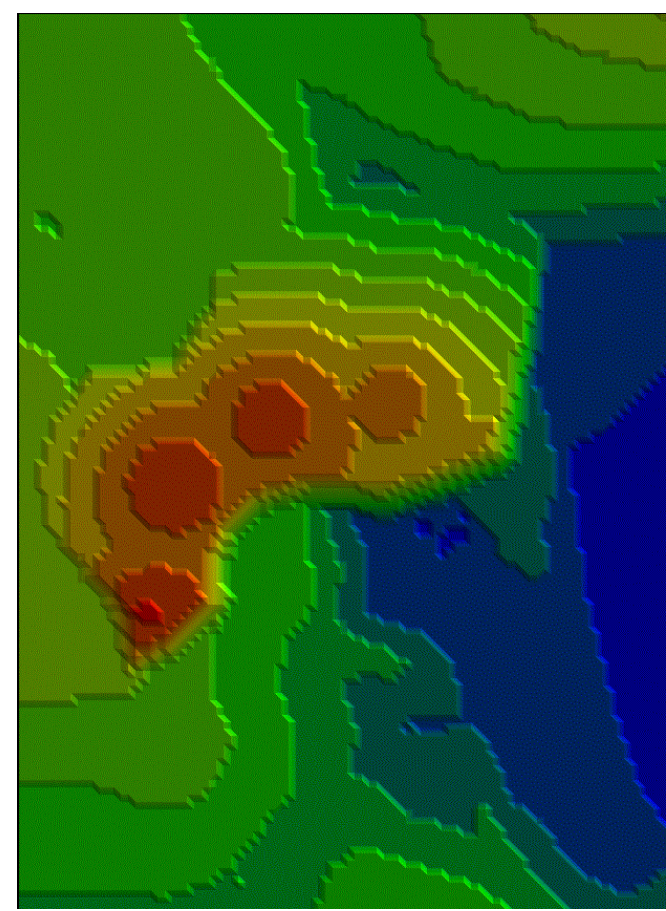

Dump profile zone 404

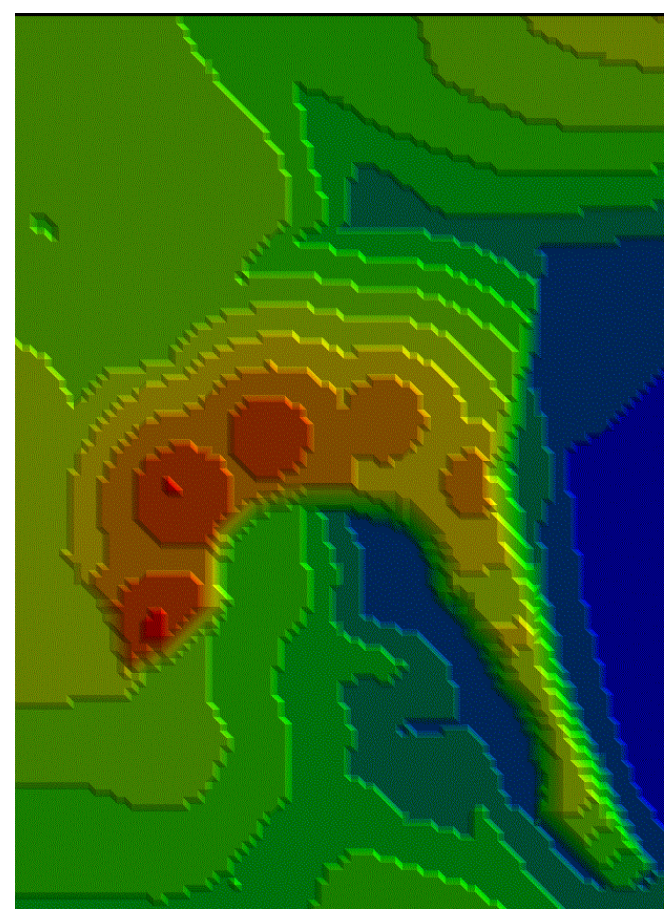

Dump profile zone 808

Figure 2 Phase 1 options analysis 


\begin{tabular}{|c|c|c|c|c|c|c|c|c|}
\hline & \multicolumn{2}{|c|}{707} & \multicolumn{2}{|c|}{404} & \multicolumn{2}{|c|}{505} & \multicolumn{2}{|c|}{808} \\
\hline & Volume & Cost & Volume & Cost & Volume & Cost & Volume & Cost \\
\hline & $\mathrm{DCM}$ & $\$$ & $\mathrm{DCM}$ & $\$$ & $\mathrm{DCM}$ & $\$$ & $\mathrm{DCM}$ & $\$$ \\
\hline Dump Entry 1 & $21,425,000$ & $11,339,711$ & $16,250,000$ & $7,816,450$ & $14,025,000$ & $6,442,999$ & $13,125,000$ & $5,912,510$ \\
\hline Dump Entry 2 & $72,350,000$ & $39,783,410$ & $48,850,000$ & $24,244,644$ & $37,625,000$ & $17,619,373$ & $33,225,000$ & $15,159,847$ \\
\hline Dump Entry 3 & $83,000,000$ & $41,232,420$ & $79,800,000$ & $37,165,168$ & $65,050,000$ & $28,484,574$ & $59,650,000$ & $25,446,041$ \\
\hline Dump Entry 4 & $71,050,000$ & $30,543,195$ & $105,550,000$ & $46,687,030$ & $90,600,000$ & $37,420,013$ & $84,850,000$ & $34,252,354$ \\
\hline Dump Entry 5 & $11,900,000$ & $5,507,960$ & $9,275,000$ & $4,220,909$ & $36,000,000$ & $12,947,758$ & $34,675,000$ & $12,225,281$ \\
\hline Dump Entry 6 & & & & & $16,425,000$ & $4,861,545$ & $34,200,000$ & $11,923,190$ \\
\hline Total Dumping & $259,725,000$ & $128,406,700$ & $259,725,000$ & $120,134,200$ & $259,725,000$ & $107,776,300$ & $259,725,000$ & $104,919,200$ \\
\hline Area Cost & & $5,120,400$ & & $6,474,450$ & & $7,030,350$ & & $7,379,700$ \\
\hline Total Dump & $259,725,000$ & $133,527,096$ & $259,725,000$ & $126,608,650$ & $259,725,000$ & $114,806,614$ & $259,725,000$ & $112,298,924$ \\
\hline Saving or Cost $(\$)$ & & $-6,918,446$ & & 0 & & $11,802,036$ & & $14,309,726$ \\
\hline$\%$ Change & & $5.46 \%$ & & $0.00 \%$ & & $-9.32 \%$ & & $-11.30 \%$ \\
\hline
\end{tabular}

The conclusions from the phase one programme were as follows:

- Zone 202 has insufficient capacity for the landform.

- Zone 707 has only just sufficient capacity and is expensive.

- Zone 404 (the base case) uses five ramps and will have stable walls with the national border to the west and north.

- Zones 505 and 808 present opportunities to save $\mathrm{A} \$ 11.8$ million and A $\$ 14.3$ million respectively compared to Zone 404. An expanded landform into Zone 505 could thus reduce average dumping costs $5.5 \mathrm{c} / \mathrm{bcm}$ and $6.5 \mathrm{c} / \mathrm{bcm}$ in Zone 808 .

- Both Zones 505 and 808 will require significant work to meet environmental approvals.

\section{$4 \quad$ Phase 2 sterilisation delay analysis}

Phase two of the study evaluated the economic impact on dumping costs of the delay that has been experienced in sterilising the ground to the east of $659,700 \mathrm{E}$ (the thick dashed line in Figure 1). Three scenarios were considered:

- No delay (the base case).

- 12 month delay (the likely case).

- 24 month delay (the worst case).

The costs calculated for scenario comparison are dumping costs and exclude area costs. The delay analysis was based on a block-by-block cash flow evaluation using the detailed mining schedule which was developed on quarterly increments for the first 11 periods, and then annual increments for the remaining production life.

The evaluation used the same cost criteria prepared for the phase one programme. The entry point ramp system was replaced with the more sophisticated approach which described a three-dimensional ramp system which would simulate an Apache pass ramp system. The Apache pass ramp system described in phase three is designed to enable semi-permanent access to every lift in the landform until the lift has been completed. This allows NPV dumping. Once a lift has been completed, the Apache pass can be progressively backfilled using the bench advance tipping system.

Other design criteria for the phase two analysis were:

- $10 \mathrm{~m}$ lift height.

- Angle of repose of dumped material 37 degrees. 
- Final overall maximum face angle (for inner pit wall) 15 degrees.

- Minimum berm width as dumped of $23 \mathrm{~m}$.

- $\quad 30$ m wide ramps at 1:10.

The screen images below illustrate perspective views of the progressive dumping sequence for the 12 month delay case. Similar dumping sequences were prepared for the "no delay" and 24 month delay cases.

Period 1 - Q2 (pre-production 2007)

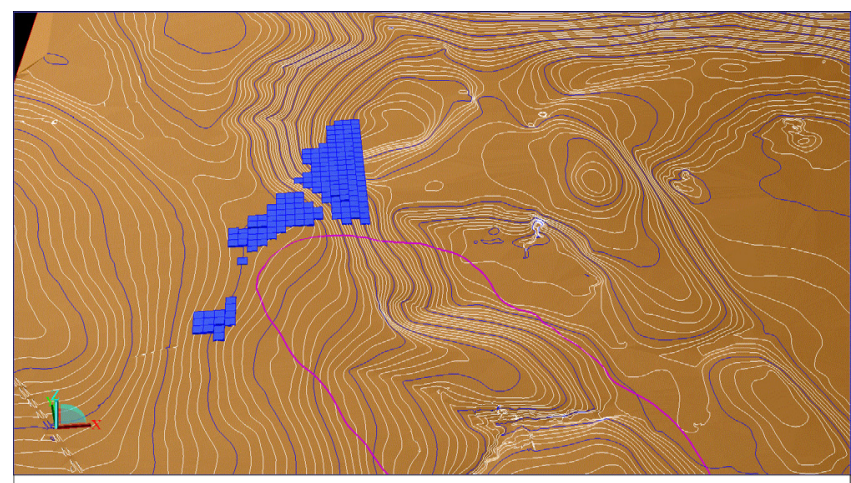

Period 5-2008 Q2

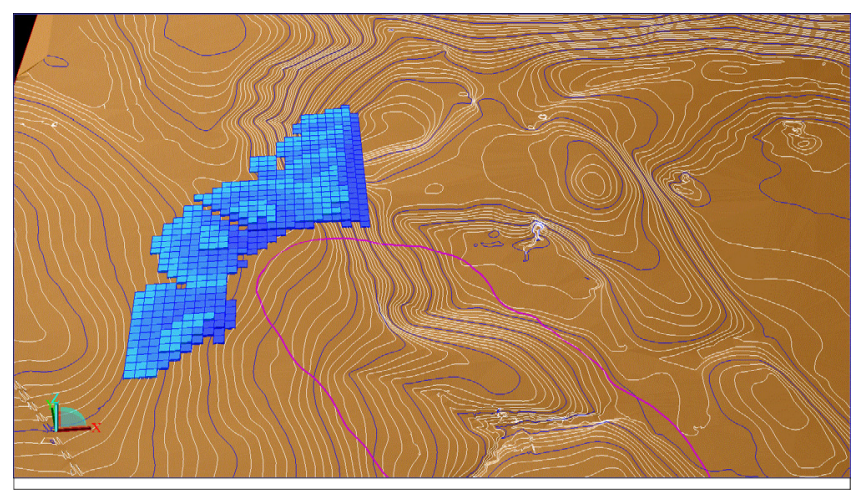

Period 7 - 2008 Q4

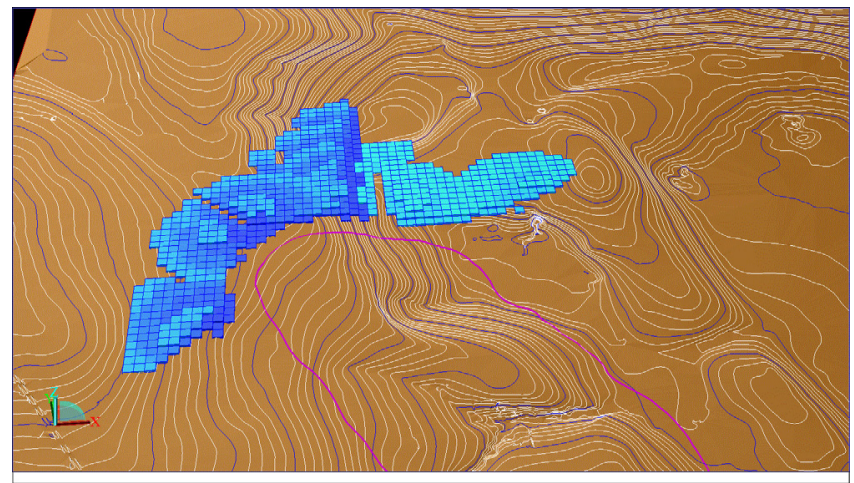

Period 11-2009 Q4

\section{Period 2 - 2007 Q3 (restricted dumping)}

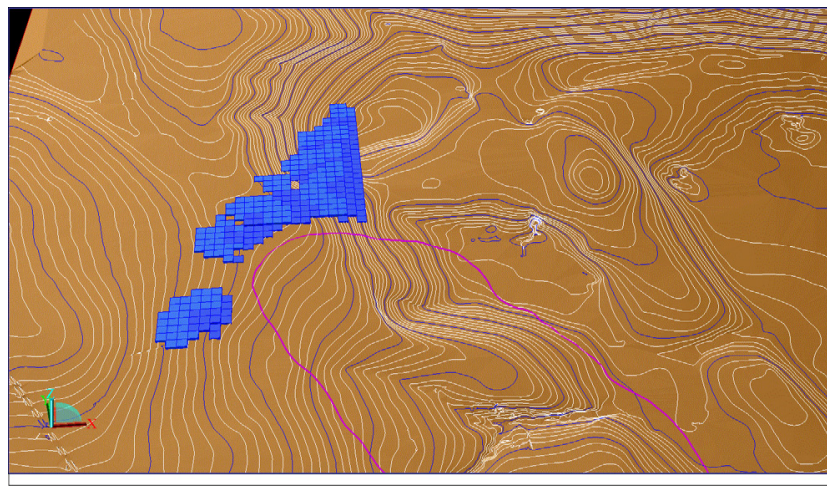

Period 6 - 2008 Q3 (sterilisation complete)

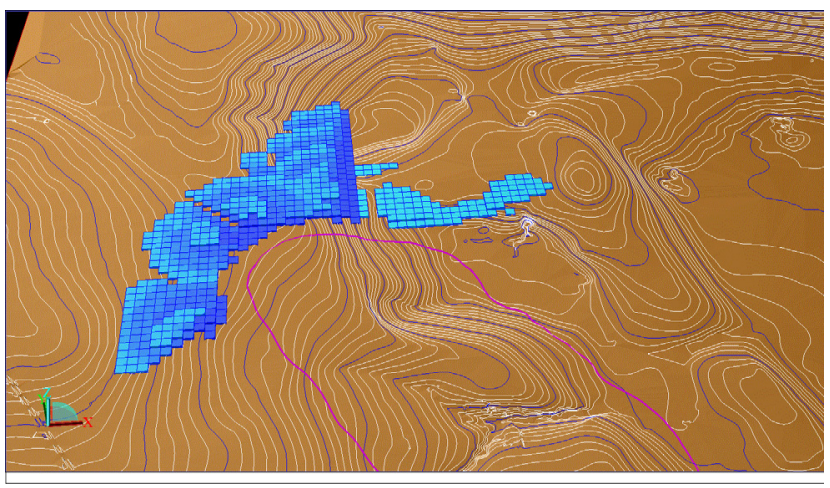

Period 9-2009 Q2

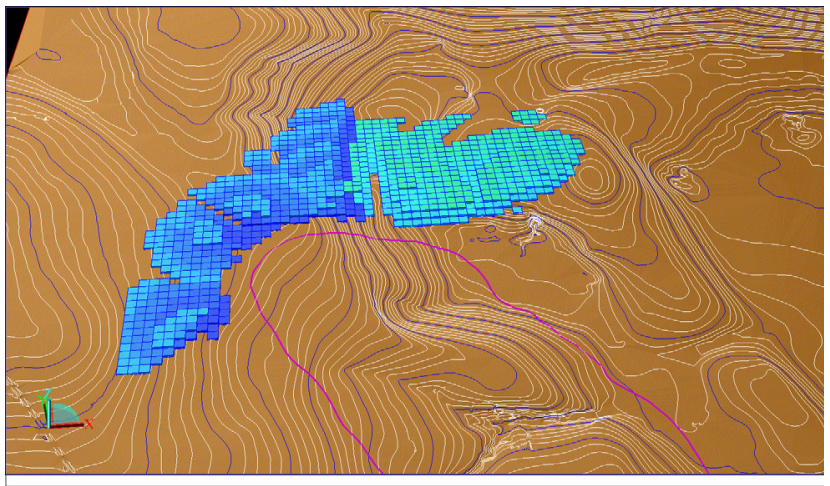

Period 13 - 2011 (dumping restarts on west) 


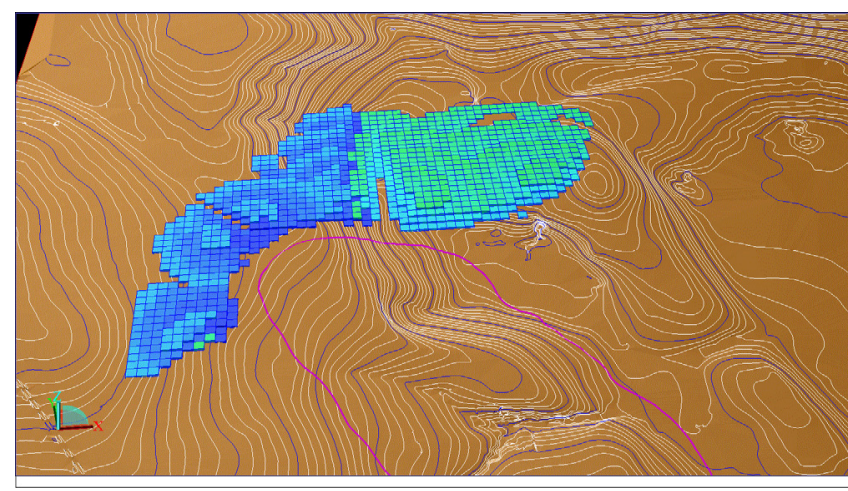

\section{Period $15-2013$}

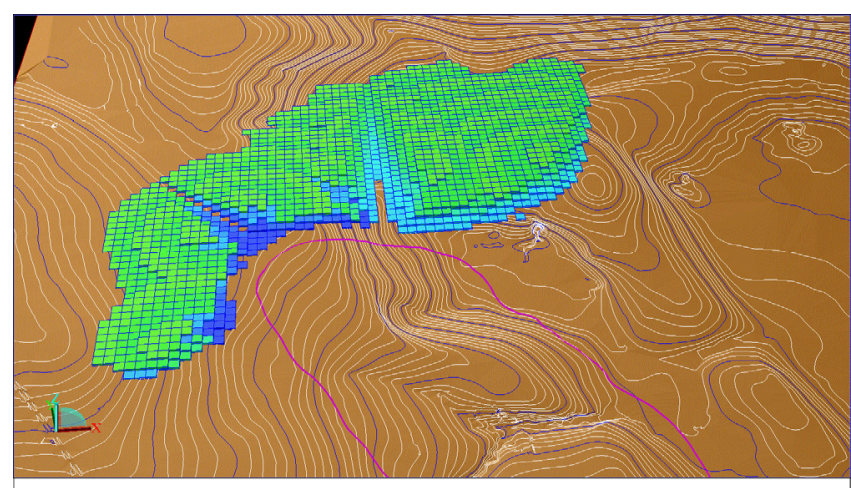

Period $19-2017$

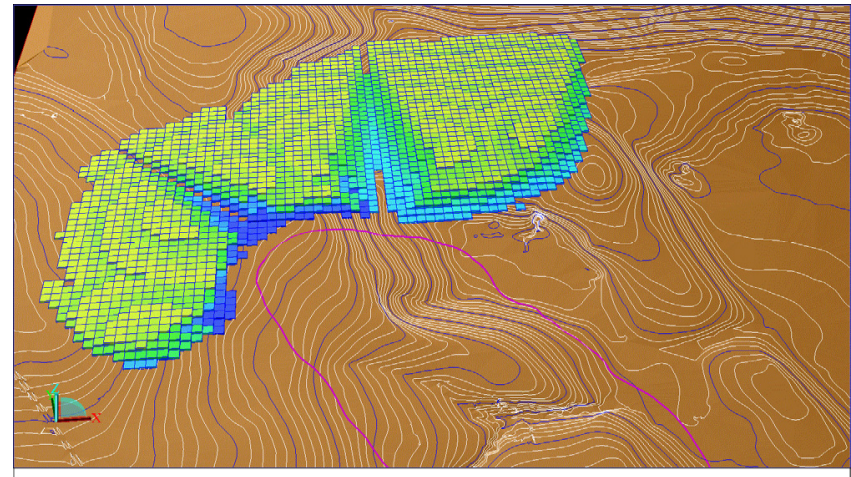

Period $23-2021$

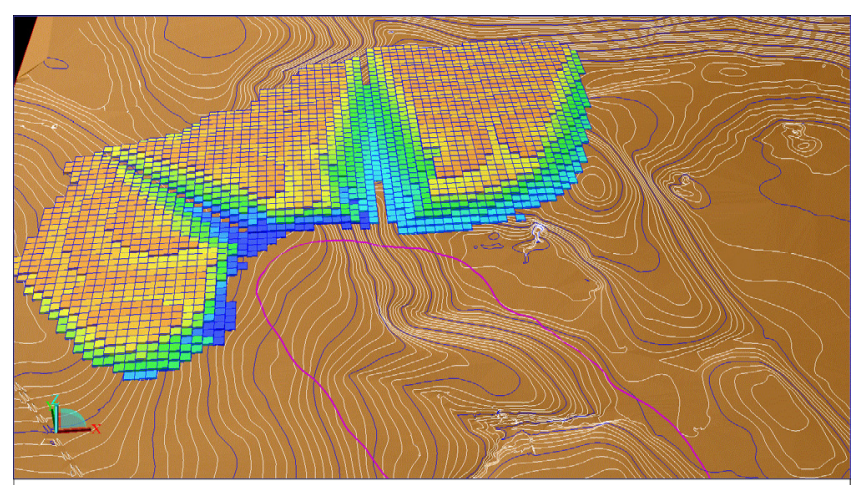

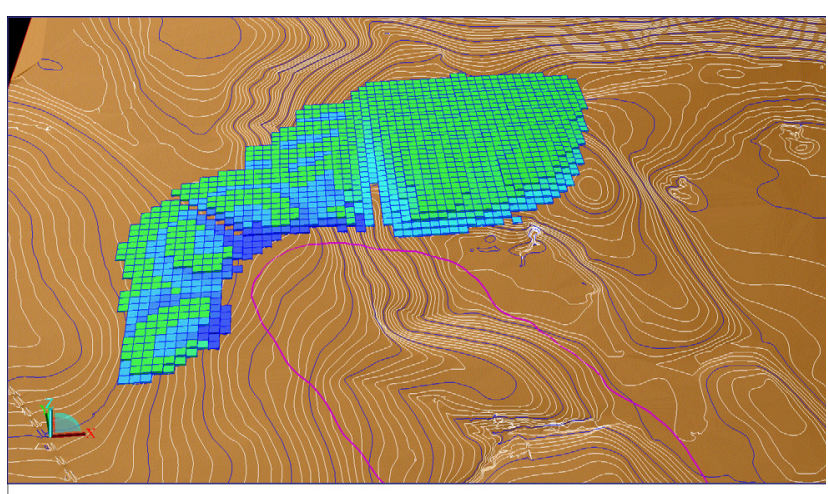

Period $17-2015$

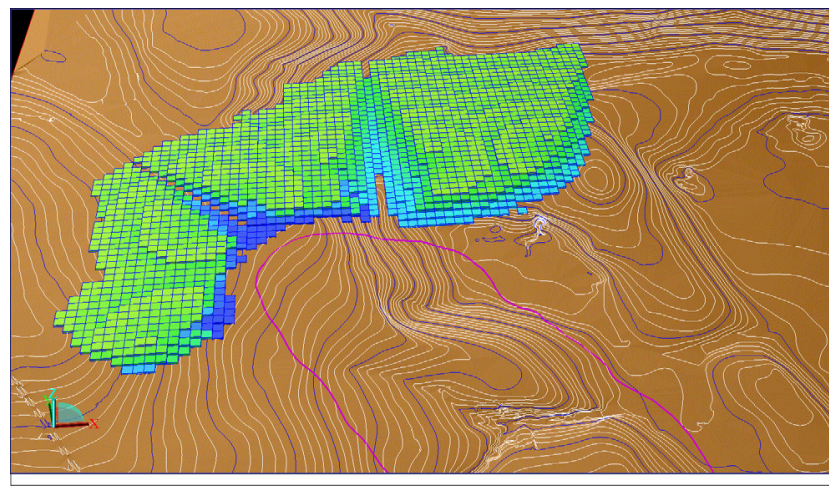

Period $21-2019$

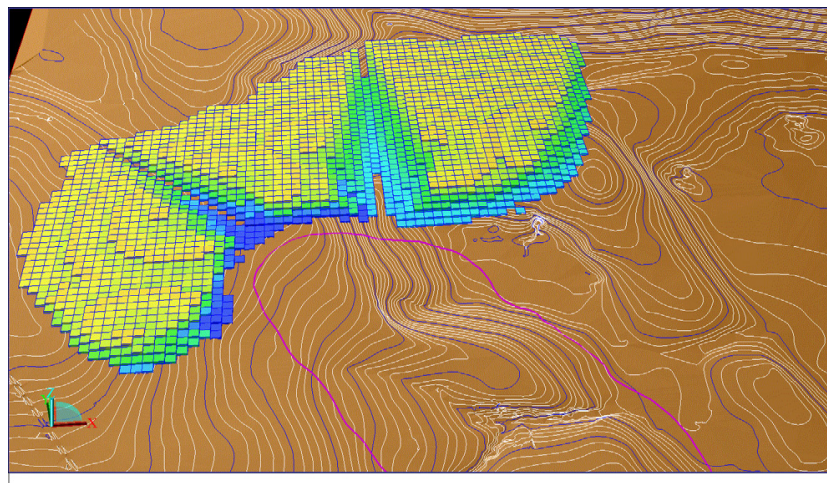

Period 27 - 2025 (project complete)

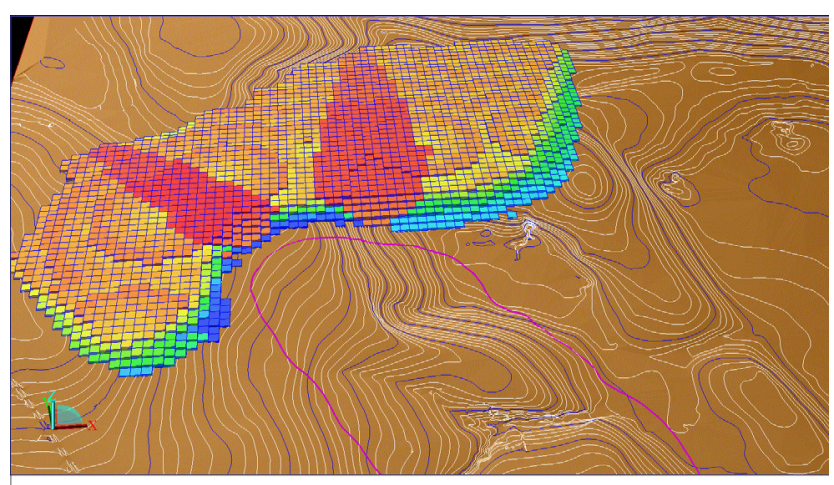

\section{Figure 3 Sterilisation delayed 12 months dumping sequence}

The results of the analysis are presented in Table 3. 
Table 3 Delay analysis dump cost cash flow

\begin{tabular}{|c|c|c|c|c|c|c|c|}
\hline & & \multicolumn{6}{|c|}{ Cash Flow } \\
\hline Period & Date & & Nil delay & & nth delay & & mth delay \\
\hline 1 & Jan-07 & $\$$ & 891,038 & $\$$ & $1,378,407$ & $\$$ & $1,378,407$ \\
\hline 2 & Jul-07 & $\$$ & 918,868 & $\$$ & $1,333,615$ & $\$$ & $1,333,615$ \\
\hline 3 & Oct-07 & $\$$ & 856,517 & $\$$ & $1,224,822$ & $\$$ & $1,224,822$ \\
\hline 4 & Jan-08 & $\$$ & 447,679 & $\$$ & 633,013 & $\$$ & 633,013 \\
\hline 5 & Apr-08 & $\$$ & $1,045,896$ & $\$$ & $1,455,205$ & $\$$ & $1,455,205$ \\
\hline 6 & Jul-08 & $\$$ & 803,258 & $\$$ & 389,835 & $\$$ & $1,107,156$ \\
\hline 7 & Oct-08 & $\$$ & $1,369,098$ & $\$$ & 947,543 & $\$$ & $1,891,451$ \\
\hline 8 & Jan-09 & $\$$ & $1,178,486$ & $\$$ & 925,276 & $\$$ & $1,635,891$ \\
\hline 9 & Apr-09 & $\$$ & $1,467,508$ & $\$$ & $1,239,427$ & $\$$ & $2,034,354$ \\
\hline 10 & Jul-09 & $\$$ & $1,548,609$ & $\$$ & $1,368,628$ & $\$$ & $2,144,157$ \\
\hline 11 & Oct-09 & $\$$ & $1,148,774$ & $\$$ & $1,043,464$ & $\$$ & 473,642 \\
\hline 12 & Jan-10 & $\$$ & $4,921,660$ & $\$$ & $4,697,749$ & $\$$ & $3,327,595$ \\
\hline 13 & Jan-11 & $\$$ & $8,066,622$ & $\$$ & $8,056,466$ & $\$$ & $6,756,466$ \\
\hline 14 & Jan-12 & $\$$ & $3,114,730$ & $\$$ & $3,114,730$ & $\$$ & $2,827,230$ \\
\hline 15 & Jan-13 & $\$$ & $5,894,095$ & $\$$ & $5,894,095$ & $\$$ & $5,607,536$ \\
\hline 16 & Jan-14 & $\$$ & $6,816,344$ & $\$$ & $6,816,344$ & $\$$ & $6,787,706$ \\
\hline 17 & Jan-15 & $\$$ & $6,115,415$ & $\$$ & $6,115,415$ & $\$$ & $6,115,415$ \\
\hline 18 & Jan-16 & $\$$ & $5,521,224$ & $\$$ & $5,521,224$ & $\$$ & $5,521,224$ \\
\hline 19 & Jan-17 & $\$$ & $8,607,105$ & $\$$ & $8,607,105$ & $\$$ & $8,607,105$ \\
\hline 20 & Jan-18 & $\$$ & $7,621,602$ & $\$$ & $7,621,602$ & $\$$ & $7,621,602$ \\
\hline 21 & Jan-19 & $\$$ & $5,186,201$ & $\$$ & $5,186,201$ & $\$$ & $5,186,201$ \\
\hline 22 & Jan-20 & $\$$ & $10,210,733$ & $\$$ & $10,210,733$ & $\$$ & $10,210,733$ \\
\hline 23 & Jan-21 & $\$$ & $8,219,745$ & $\$$ & $8,219,745$ & $\$$ & $8,219,745$ \\
\hline 24 & Jan-22 & $\$$ & $5,699,101$ & $\$$ & $5,699,101$ & $\$$ & $5,699,101$ \\
\hline 25 & Jan-23 & $\$$ & $5,911,943$ & $\$$ & $5,911,943$ & $\overline{\$}$ & $5,911,943$ \\
\hline 26 & Jan-24 & $\$$ & $6,507,560$ & $\$$ & $6,507,560$ & $\$$ & $6,507,560$ \\
\hline 27 & Jan-25 & $\$$ & $1,520,902$ & $\$$ & $1,520,902$ & $\$$ & $1,520,902$ \\
\hline
\end{tabular}

Table 3 results show that the additional cost incurred to date (January 2007) by forcing the fleet to construct the waste landform on the western side of $659700 \mathrm{E}$ is the cash flow from the 12 month delay in period 1 less the cash flow from nil delay for the same period, or approximately $\mathrm{A} \$ 480,000$.

The cumulative costs for each scenario were calculated and then plotted on the same chart (Figure 5). The bottom line represents the "no delay" scenario. The 12 month (middle dashed line) and 24 month (upper solid line) delay lines follow the same track until Period 6. At this point, the cumulative differential cash flow between the no delay case and the delay cases will be $\$ 1.86$ million. This marks the point in time when the quarantine imposed on the east side of the dump is relaxed and the 12 month delay dumping costs will equalise with the no delay case. For the 24 month delay scenario, the cumulative differential cash flow will continue to balloon to $\$ 4.31$ million until it trends towards the no delay costs as the east side of the dump is rapidly filled.

If the cash flows are annualised and then discounted at $10 \%$, the 12 month delay has reduced the NPV of the project by $\$ 0.25$ million and if the drilling is delayed by a further 12 months, the NPV will be reduced by almost $\$ 0.9$ million. While the loss in value is not high, it does illustrate a simple oversight in one small aspect of a project can have adverse effects on the NPV. While the optimisation process itself has limited the losses, another loss mitigating factor is the relatively low waste volumes to be mined in the early years of the project due to deferred waste stripping. 


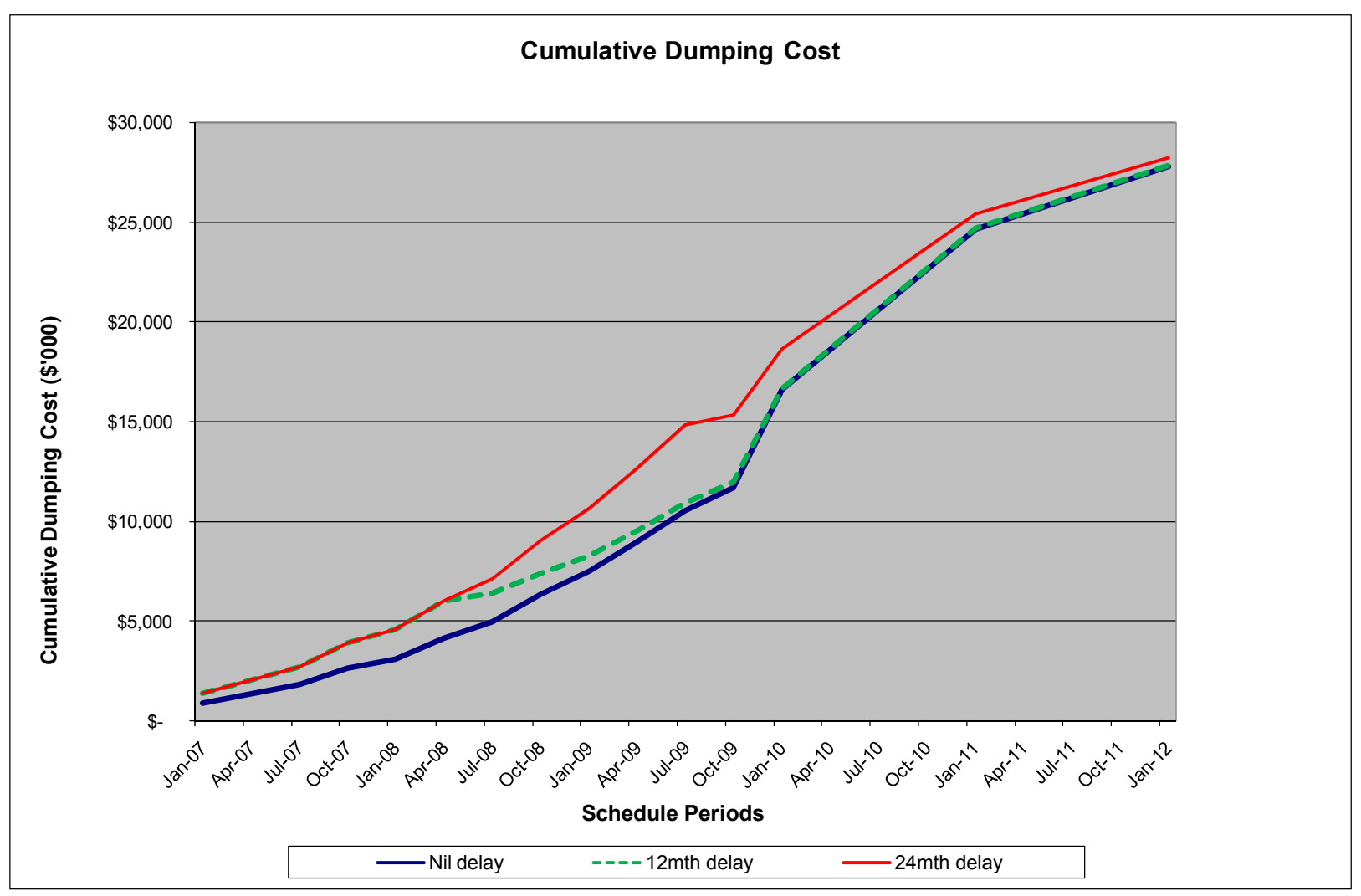

\section{Figure 4 Cumulative dumping cost}

\section{$5 \quad$ Phase 3 detailed waste landform design}

Waste landform designs were prepared using conventional mine planning software to show the progressive construction of the landform from the present to projected mine closure. The process used the 12 month delay model as this is the most likely scenario.

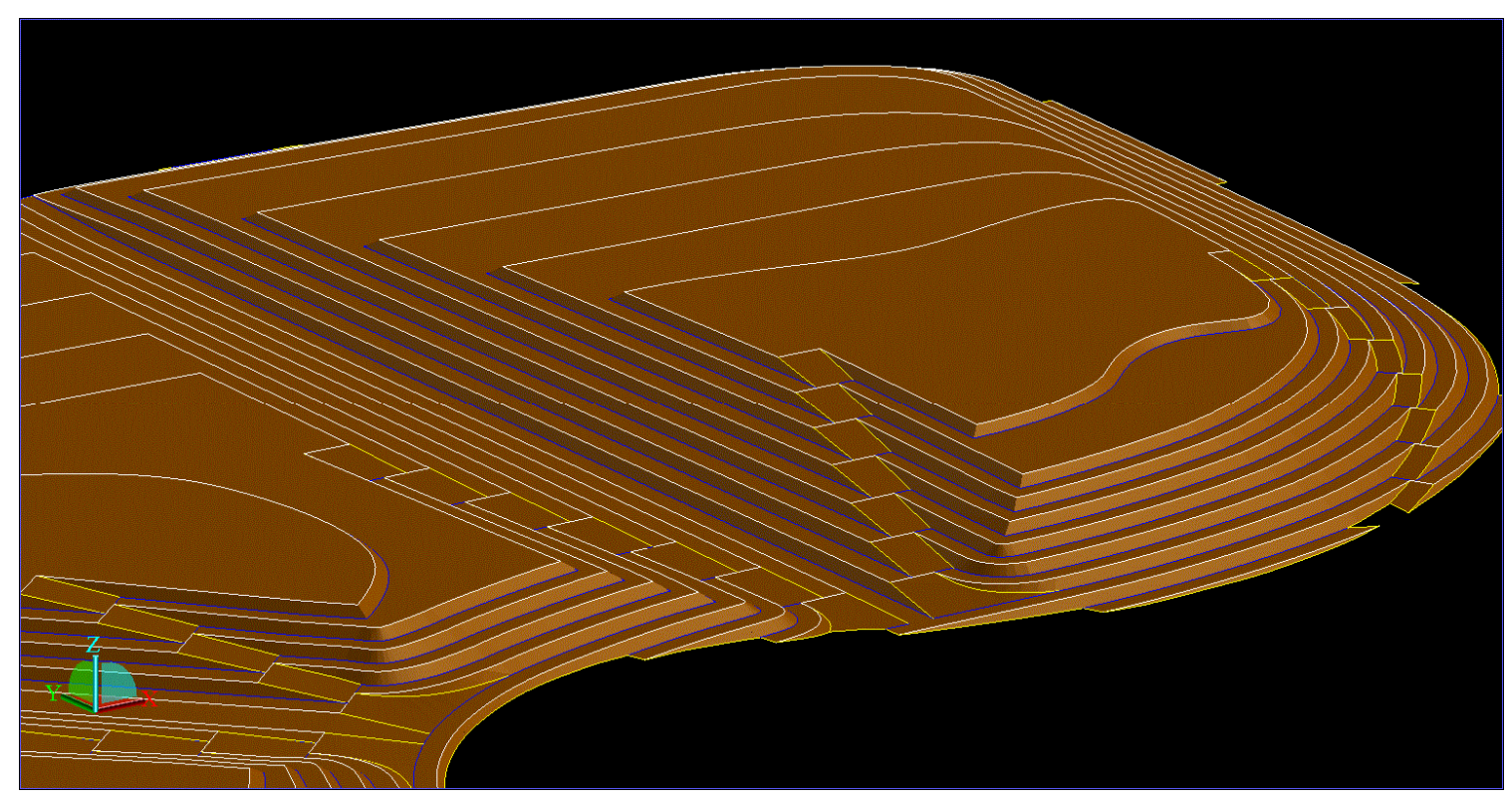

Figure 5 Apache pass system 
The dump block sequence was used to guide the practical landform design which comprised "as-dumped" crest and toe lines with progressive ramp layouts. In order to achieve the NPV dumping sequence, multiple tip-heads will be required and this will require the development of Apache pass ramp systems.

The Apache pass haul road system is illustrated in Figure 5. Semi-permanent access roads are maintained to each lift of the landform and each dump lift will be progressively extended until the final toe position is reached. Once the lowest lift on the landform has been completed, this portion of the Apache pass can be filled using a bench advance tipping method. Generally, filling of the Apache pass will be the last portion of the landform to be built and provides an opportunity for short haul dumping near the end of the pit life.

With the establishment of multiple tip-heads, there is maximum operational flexibility. In this case, each tiphead will be $10 \mathrm{~m}$ high. The Apache pass system discourages formation of high tip-heads which can become unstable. Also high tip-heads are a very inefficient method of creating waste landforms. An enormous quantity of potential energy will be expended to haul a truck and its payload to the top of a high waste dump then when the waste material is tipped and rills down the slope, the potential energy is lost. This lost potential energy is represented largely by high fuel consumption. Furthermore, haul trucks travel very slowly uphill when loaded and the result will be higher cycle times.

On the negative side, an Apache pass system may comprise $10-15 \%$ of the total capacity of the waste landform. NPV dumping eliminates the ability to progressively rehabilitate blocks located on the extreme outer edge of a landform until construction is complete. However, portions close to the pit and on the flanks of the landform will become available for rehabilitation relatively quickly.

The progressive formation of the wrap-around landform is illustrated in Figures 6 to 10. The analysis concluded that the landform cost (area costs plus ex-pit haul costs) will be $\$ 0.54 \mathrm{c} / \mathrm{bcm}$.

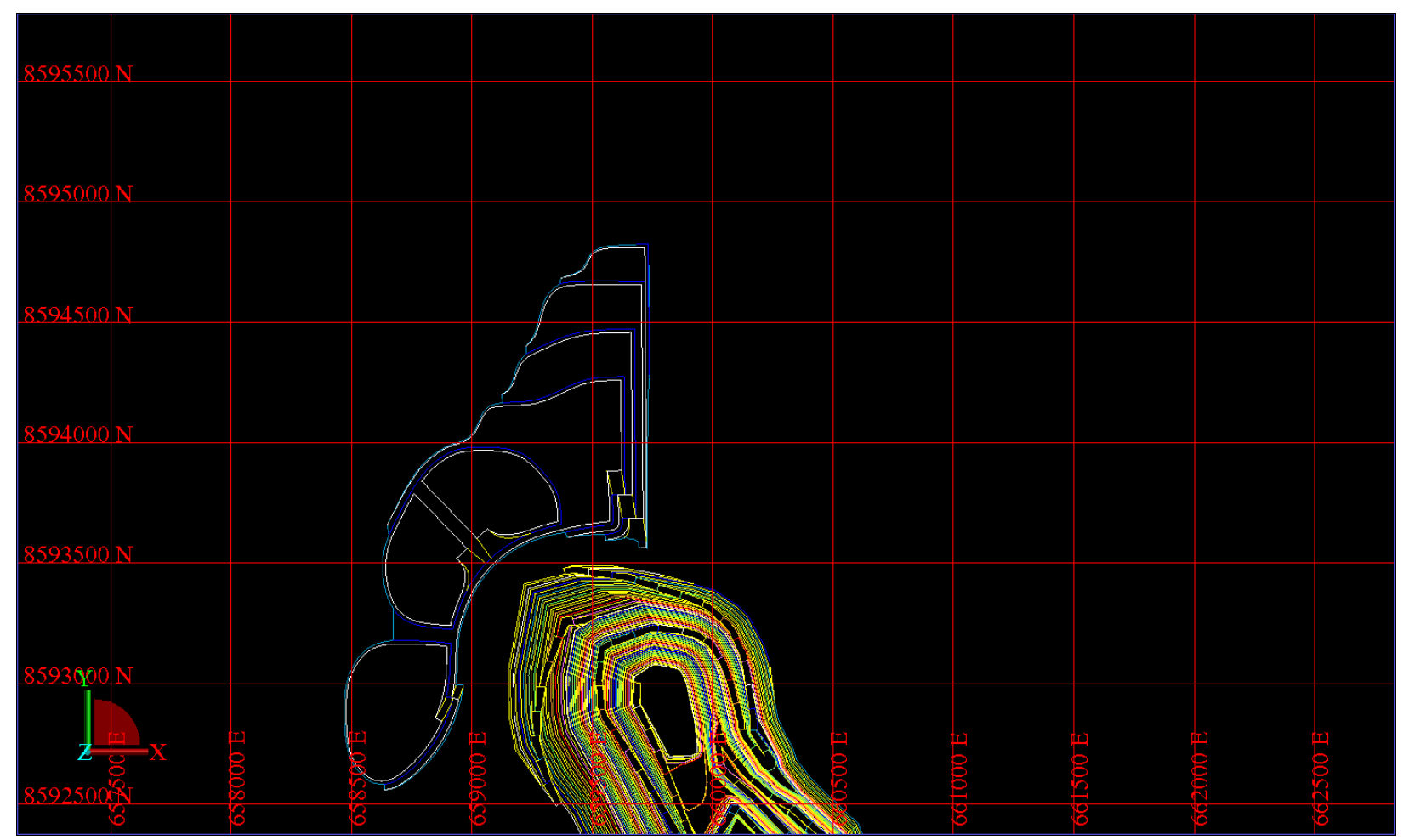

Figure 6 Landform layout year 2007 


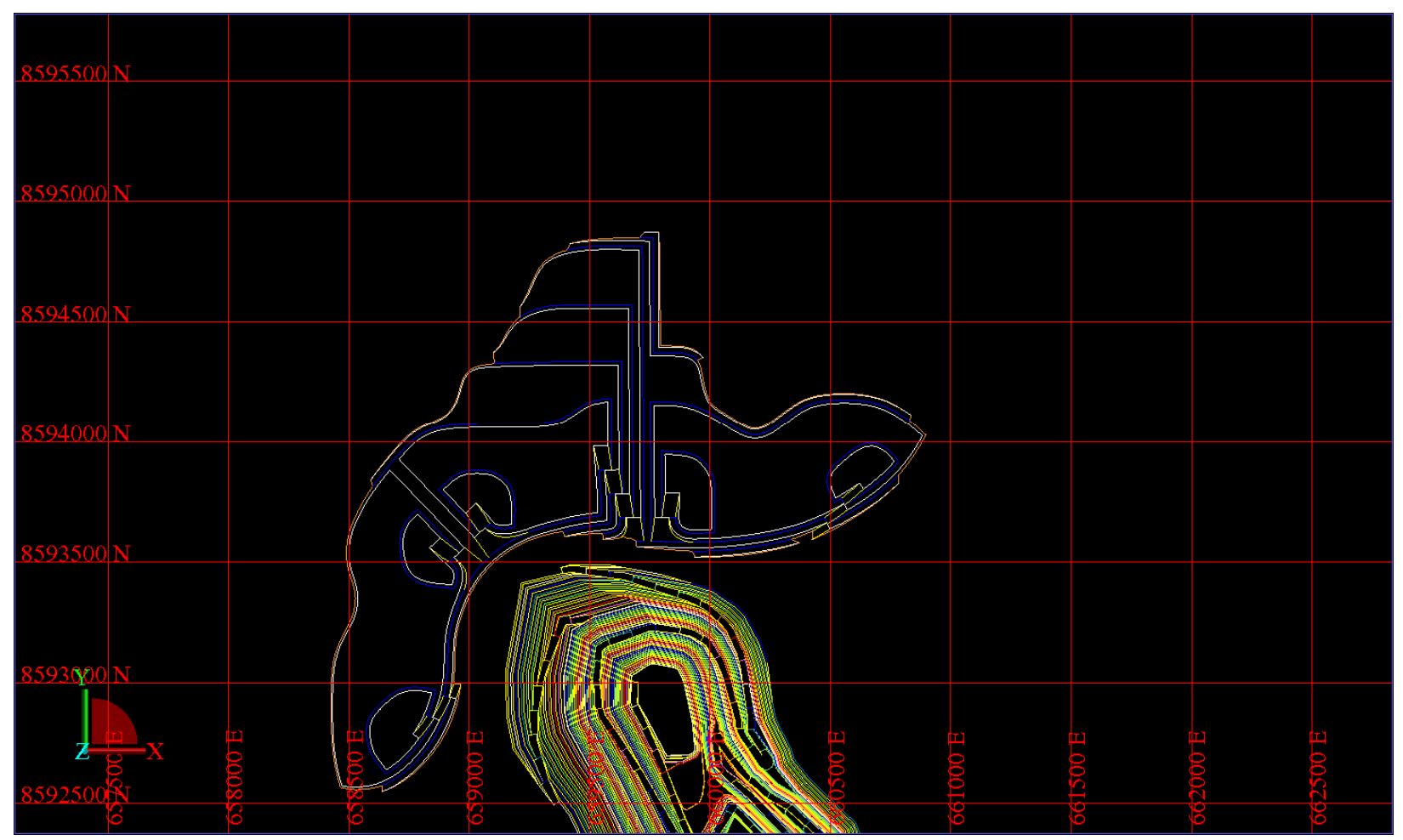

Figure 7 Landform layout year 2008

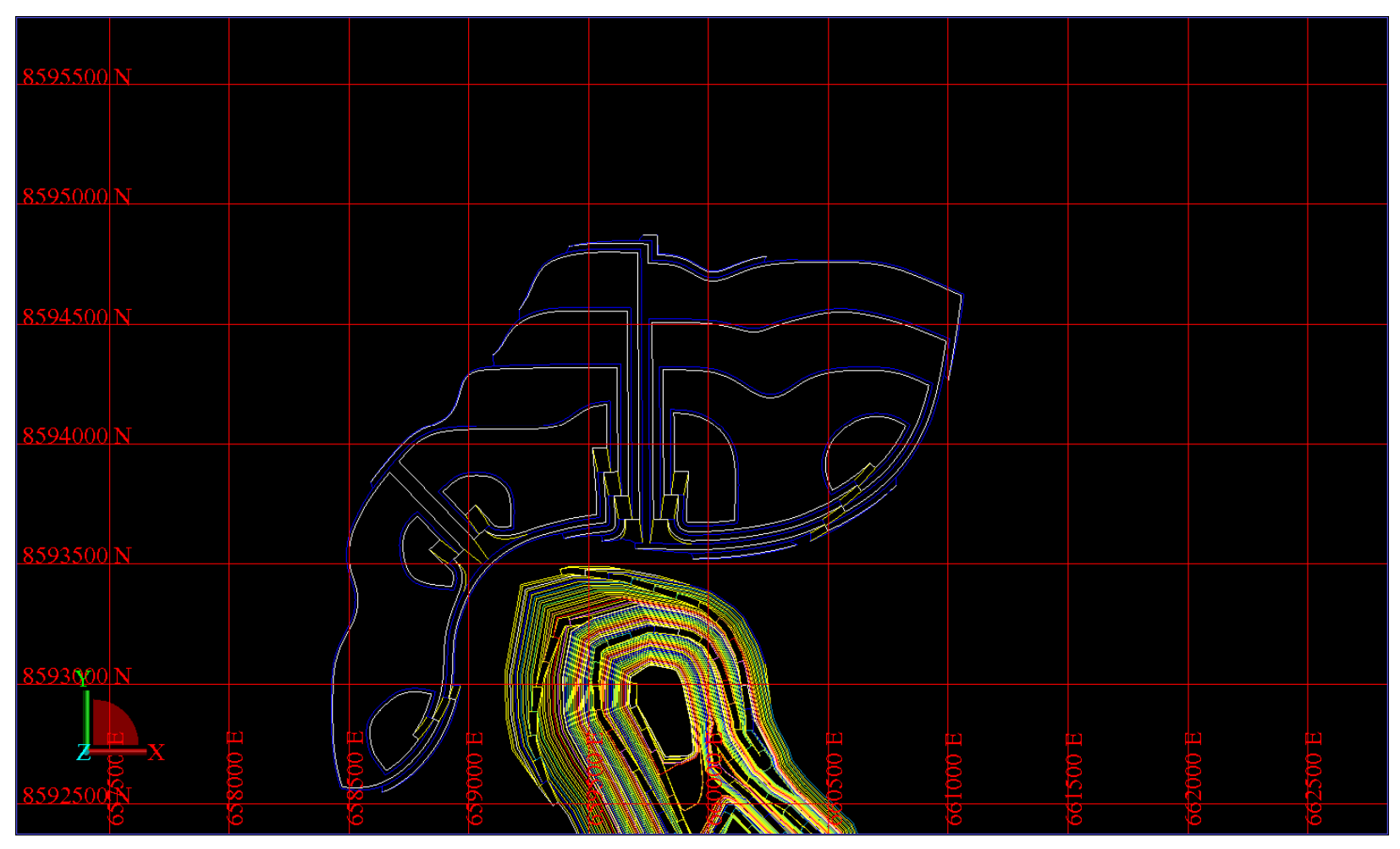

Figure 8 Landform layout year 2009 


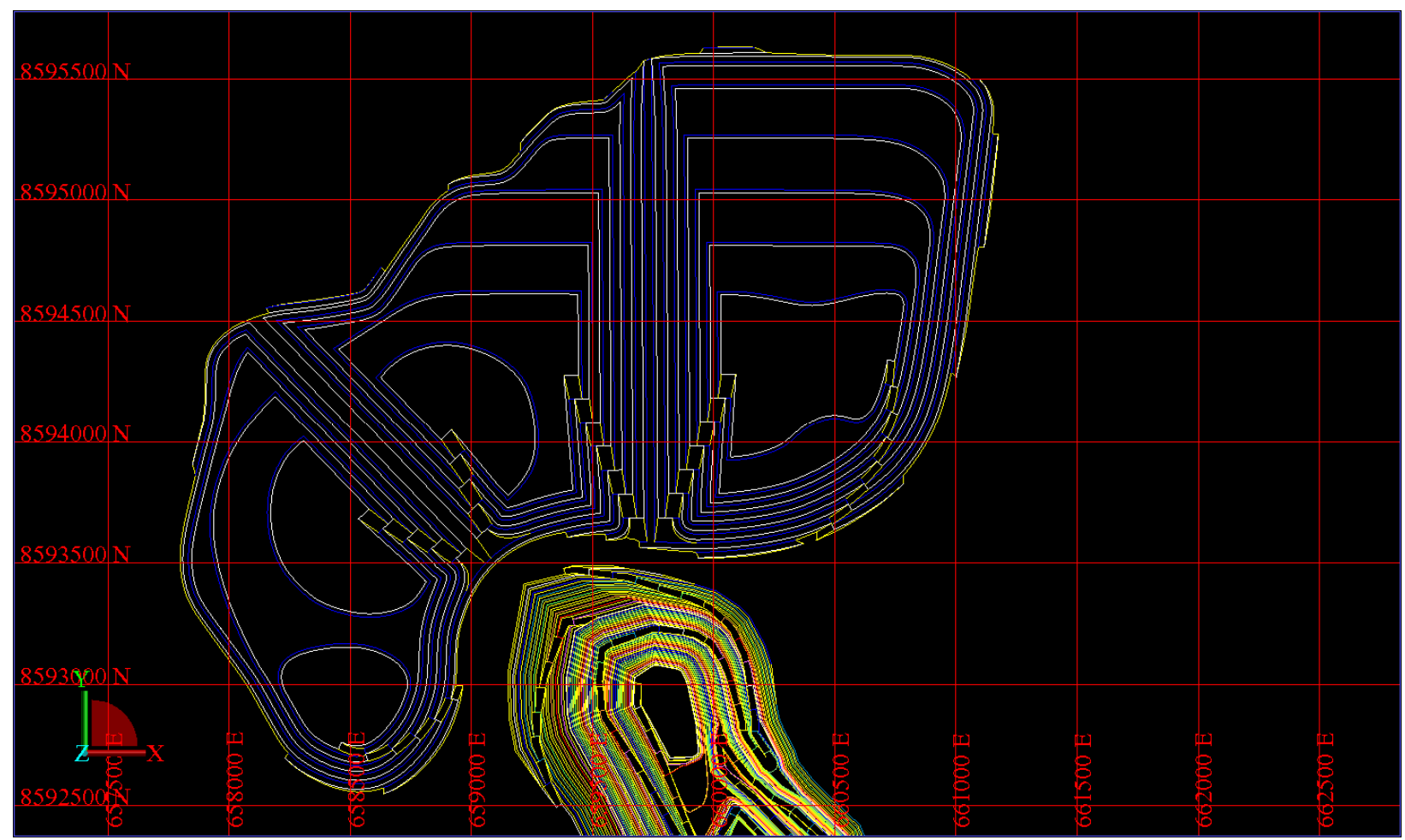

Figure 9 Landform layout year 2021

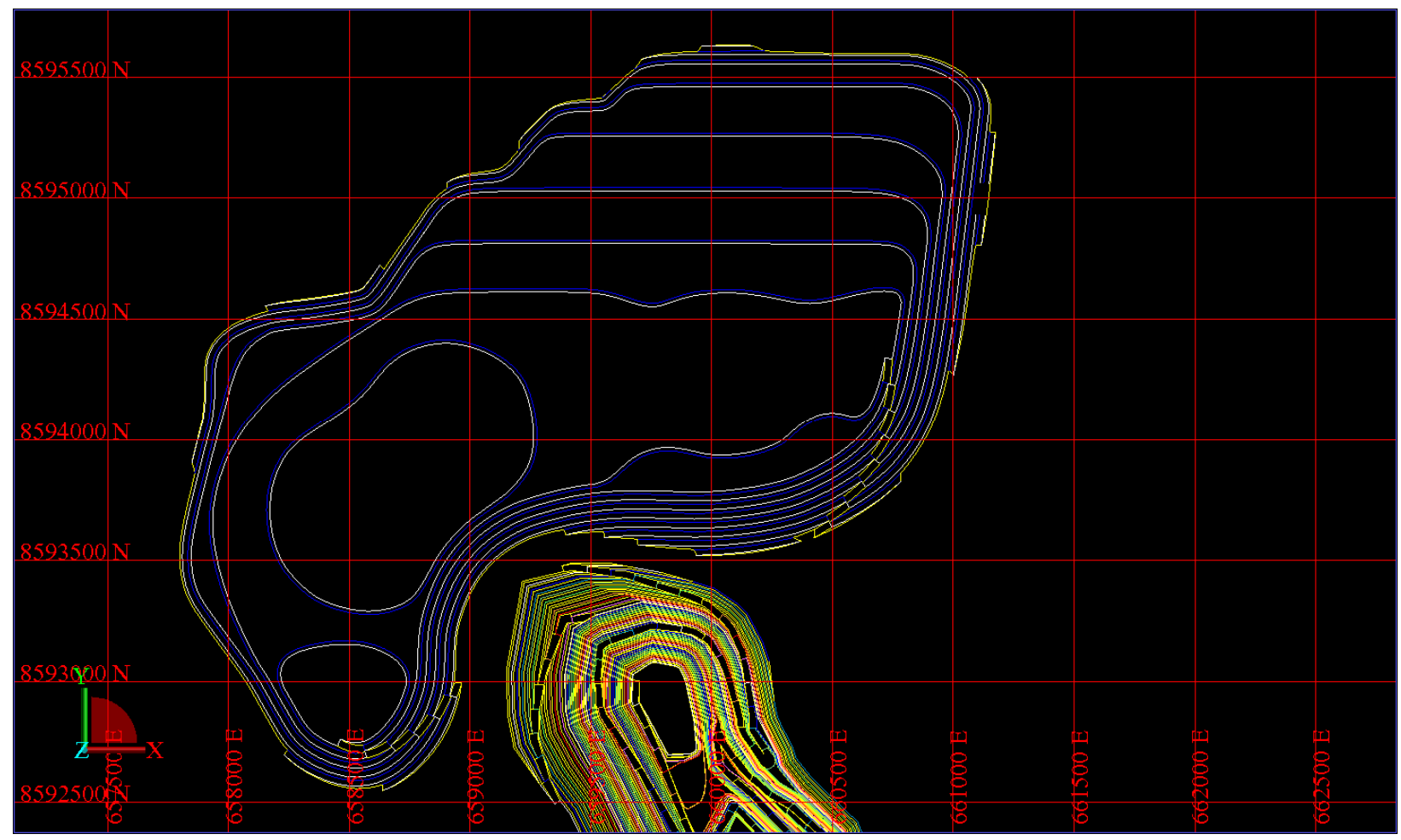

Figure 10 Landform layout year 2024

\section{Conclusion}

The final phase of the programme selected the most likely operating scenario and used the results to prepare a detailed dump sequence which will be used to guide the mining operation and progressive construction of the waste landform. The detailed designs incorporate "Apache passes" which show how semi-permanent 
access can be maintained to all dump lifts throughout the majority of the life of the waste dump thereby providing opportunities to fill the cheapest blocks first in a waste landform and maximise the project's NPV. In addition, maintaining access to all dump lifts over the life of a waste dump eliminates the need to develop excessively high tip-heads and presents the following benefits:

- Safer operating environment.

- Limits potential energy losses and saves fuel.

- Reduction in overall haul cycle times.

- Individual bench heights are significantly more stable, easier to doze down and rehabilitate. 